\title{
Experimental research on the formation of mineral-rich areas in residue gold placer deposits
}

\author{
Vladimir Alexeev ${ }^{* 1}$ and Tamara Banshchikova ${ }^{1}$ \\ ${ }^{1}$ Mining Institute of Far eastern branch of Russian Academy of Sciences, Khabarovsk, Russia
}

\begin{abstract}
Underestimation of the reserves of raw material base of gold mining (namely residue dump complexes) leads to negative social and economic consequences in the regions engaged in placer gold mining. Nonetheless, their efficient development is possible only through the use of new rational technologies of preparation and deep processing of rock mass for subsequent extraction of valuable minerals. In order to create such a technology, large-scale research was made on the nature and degree of the influence that the basic factors of the technology have on the process of migration and concentration of gold particles in a residue rock mass. Key words: residue placer deposits, cryogenic processes, suffusion, filtration flows, gold particles migration, mineral-rich areas formation.
\end{abstract}

\section{Introduction}

Exploitation of placer gold deposits of non-ferrous metals, noble and rare metals is of significant importance to Russian Far East, and, despite the discouraging forecast regarding the exhaustibility of natural resources, their development will carry on over many years. Placer deposits include all the basic characteristics of geologic system that reflects the unity and interconnection of the components such as mineral resources, natural processes, technique and technologies, social and economic structures, system organization, production activity, etc. [1].

According to the specialists' estimation [2-6], residue placers possess a great potential. Some gold-mining areas have accumulated significant amounts of auriferous dump complexes - billions of cubic meters of gravel dumps, peats, etc.

The need for a more careful and constructive attitude to the problem of increasing gold extraction out of placer deposits is also connected with ecological state of placer goldmining areas. The waste products from the primary geogenic deposits have a negative influence on the natural environment, considering that amounts of their rock mass are over 2 billion cubic meters in Far East of Russia alone.

Residue placer deposits are significant reserves of mineral resource base of noble metals, but their development is complicated due to the fact that valuable components in a massif are in chaotic, scattered state, and their extraction is connected with full processing

*Corresponding author: alekseev-vs_83@mail.ru 
of all residue formations, which often proves to be unprofitable because of the significant material costs and expenses. Therefore, the problem of finding an efficient method of placer deposits development is acute and is of great financial and social importance.

The research on the residue formations of placer deposits has led to the foundation of in-dump enrichment of a placer deposit, where the particles of noble metals migrate and concentrate into lower layers of the mountain massif, which is chiefly driven by natural factors. These factors include the following processes: hydrodynamic process, including the processes of filtration and suffusion, cryogenic processes and microseismic processes. Significant similarity in genetic technologic nature was found in the analogous processes natural processes of placer deposit formation, particularly geological differentiation of mineral matter. The term "differentiation" is used to characterize many geological processes, in which primary mineral resources form byproducts that are genetically similar to them but have a different structure or traits.

Unlike the processes of formation of mineral-rich areas of residue placer deposits, the geological differentiation of mineral matter is a lot more time-consuming, although it is necessary to know its characteristics to estimate all the factors that aid in the migration of valuable components of alluvial rock mass into a bedrock-adjacent area of dump complexes. The differentiation of mineral rock mass of residue dump complexes of placer deposits reflects the processes of selective formation of productive layer, i.e. natural division and displacement in rock mass of residue dump complexes of valuable component separate monofractions and enclosing rocks relative to each other depending on their morphological, granulometric, hydraulic and physical characteristics, which is driven by natural and anthropogenic processes $[8,9]$.

One of the characteristics of residue placer deposits is the stochastic nature of gold distribution and other valuable components in a massif, which, in the process of exploration, determines the need for the development and overall enrichment of the rock mass. Therefore, when the amount of valuable components is insufficient, the attempts to process residue placer deposits prove to be futile. For this reason, the formation of residue placer deposits of new kind with selective position of productive layer of sands in lower strata is a major scientific and practical problem. As a rule, a bedrock-adjacent mineral-rich layer is characterized by its homogeneous structure, relatively small amount of productive rock mass, which allows for a more economic and technologic development of residue placer deposits.

The technology itself is the following [10, 11]: a drainage ditch and an accumulating ditch are created in the upper and lower parts of the block of residue sands, which entails the formation of a filtration flow in the block afterwards, and this flow allows the gold particles to move vertically. If such a flow is continuous, it leads to the formation of a mineral-rich layer of sands in the bedrock-adjacent part of the block. It allows for the separation of sands with lower contents of gold and reduces the range of washout.

In order to study the processes, lying in the bases of the technologies, laboratory researches were made in 2008-2009. They were focused on the influence of cryogenic processes on the efficiency of gold particles migration [10]. The results are: the more freeze-thaw actions happen, the deeper is gold distributed based on the capacity of the rock mass; $0,25 \mathrm{~mm}$ fraction of gold migrated across the whole depth of the rock mass, where $7.1 \%$ of this fraction reached the bottom; cryogenic processes as an independent factor have little influence on the migration of gold particles.

The further studies were focused on the influence of the processes on gold migration. In the first experiment, gold migration was caused by free flows of water, in the second it was caused by the combination of the processes: free flows of water and freeze-thaw actions. The experiments were held simultaneously on the specially designed unit that consisted of 6 tanks $25 \times 12 \times 10 \mathrm{~cm}$, and each of them was connected to a pipeline with the function of 
regulation of water flow rate, which amounted to $10 \mathrm{l} / \mathrm{h}$. In the first five tanks, gold with certain thickness stayed on the upper layer; in the sixth tank, designed for freeze-thaw experiments, the upper layer accumulated the gold of all kinds of thickness. In each tank, the migration was caused by the filtration flow during 25 days. One of the tanks got frozen twice at a temperature of $-18{ }^{\circ} \mathrm{C}$, and after it thawed at a room temperature, the water flow continued. The results of these experiments are shown in Fig. 1.

Under the complex influence of external factors on the rock mass, gold distribution based on the output of a rock type proceeded more effectively, gold migration into lower layers increased by $20-64.3 \%$. $0.1 \mathrm{~mm}$ fraction reached the bottom of the vessel, and it was $19 \%$ more under the complex influence. Content analysis based on the rock length shows that the movement of gold particles in a horizontal plane is caused only by water flow energy.

In 2010, the research on gold migration took place in natural conditions. Holes were filled with gold fractions from placer deposit of the stream "Bolotistyi", which was a permanent source of the water flow. In winter, the rock mass was freezing, and after it thawed, it was excavated layer by layer. As a whole, the experiment lasted 300 days.

Fig. 2 accurately illustrates the change in the content of gold based on the depth relative to the original one: in the upper layer, it reduced by $62 \%$, while in the lower layer it increased by $68.9 \%$. The increase in the content was caused mainly by the migration of $0.25 \mathrm{~mm}$ fraction. The horizontal movement of the particles is insignificant, except for the water supply location.

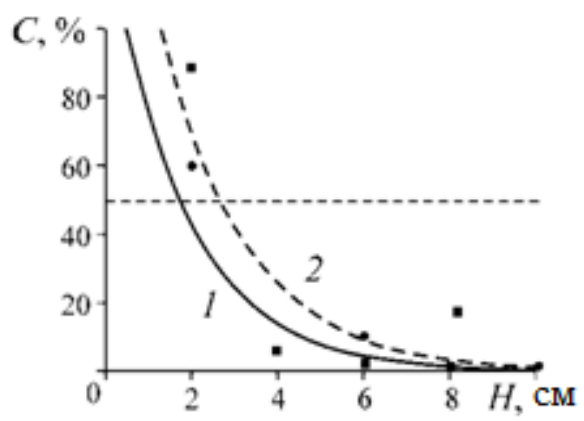

Fig. 1. Dependence of gold content in the areas of concentration on the depth of the rock mass: 1 - under the influence of free water flow; 2 - under 2 additional freeze-thaw actions

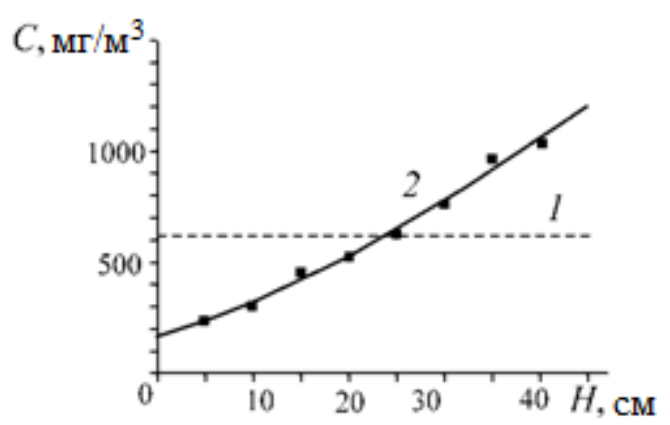

Fig. 2. Change in gold content based on the depth: $1-$ the primary gold content in a rock mass; 2 - gold content after the experiment

In 2012, industrial tests began on a test section allotted by "Ros-DV", LLC (Khabarovsk Krai). In the middle part of the deposit from the stream "Bolotistyi", developed in 20062007, in close proximity to the silt-detention basin that served as the source of technological water, there was a block of residue sand, $8 \times 15 \mathrm{~m}$ in size and $1 \mathrm{~m}$ in volume. The materials used were tailings extracted from the processing, that contained small and thin gold. The next stage implies the freezing of the block, but its thawing process generated a filtration flow during the washing process.

Before the next freezing, certain tests were selected. Their results are shown in Fig. 3a. The average content of gold in the four upper samples was $21.6 \%$ decreased in comparison to that in hole 1 , in hole $2-22.9 \%$, in hole 3 the migration is barely visible due to the unprocessed area.

Assuming the limit of the content equal to $125 \mathrm{mg} /$ tons, we will see a cut, where area 1 is the part of the block, where the content of gold reduced (overburden rocks), area 2 is a productive layer the volume of which is equal to the half of that of the sand block. The 
formation of area 3, presenting a layer of sands with high content of gold (over 125 $\mathrm{mg} /$ tons) is explained from the position of this area over the depression curve, which caused this area to not be subject to the influence of water flow, and the migration is caused by the filtration from the surface of the rainwater and "freeze-thaw" process in the rock mass.

In October 2014, (the experiment lasted 2 years), several samples were selected from the test section, and the result of their beneficiation is illustrated in Fig. 3b. The average content of gold in the five upper tests reduced by $21.2 \%$ in comparison to that in hole 1 , $8.7 \%$ in hole 2 , and $24.4 \%$ in hole 3 . Thus, during the 2 washing processes, it was possible to form a mineral-rich layer (with over $125 \mathrm{mg} / \mathrm{t}$ ), the volume of which is $44 \%$ of overall volume of the sands in the experimental block.

The obtained data may be used to expand the theoretical knowledge of the process of gold particles migration, and develop the methods of calculating the basic parameters of the technology that is capable of controlling the factors influencing gold migration.
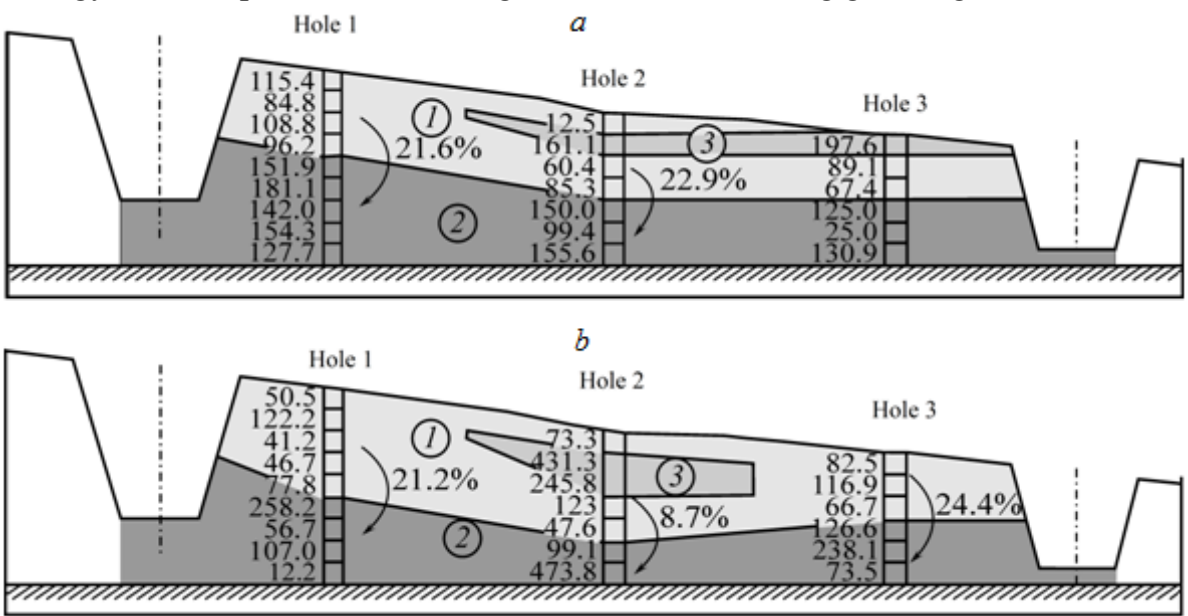

Fig 3. Cross-section of the sand block in 2013 (a) and 2014 (b): 1 - overburden, 2 - productive layer, 3 - unprocessed area.

The main source of increasing the effectiveness of the developed technology is the foundation of the cycle of forming a free flow of process water, which would allow for a significant decrease in its flow rate.

In 2015, for the purpose of studying the influence from the cyclic flood-and-drain process of the rock mass of the residue placer deposit on the migration of gold particles, a laboratory research was held.

2.5-liter tanks were filled with a rock mass with water supply to create a filtration flow. The rock mass was imparted with equal amount of gold fractions: $-1+0.5 \mathrm{~mm}-150 \mathrm{mg}$, $0.5+0.2 \mathrm{~mm}-50 \mathrm{mg},-0.2 \mathrm{~mm}-28.8 \mathrm{mg}$.

The water supply to tank 1 is constant, to tank 2 - cyclic, and the flood-and-drain process implied 5 days of constant water supply, 2 days of draining; the gold was placed evenly upon the whole volume of the rock mass; process water flow rate in each tank was $12.51 / \mathrm{ph}$.

After 25 weeks (25 flood-and-drain cycles), the water supply was stopped, the selection of samples is conducted layer by layer skipping $2 \mathrm{~cm}$. The analysis of the laboratory research emonstrates the following:

with constant water supply, the content of gold in the 2 upper layers reduced by more than $50 \%$ in comparison to the original; the increase of gold content in the third layer was $24.5 \%$, in the second $-38.0 \%$, in the third $-30.4 \%$; the nature of the change in gold content in different fractions in the same: a little decrease in the upper layer, significant 
decrease in the second and an increase in the layers below.

- with cyclic water supply, the maximal change in gold content was $4.6 \%$ in comparison to the original; it is possible to observe the migration of only the particles from $0.5+0.2 \mathrm{~mm}$.

In 2016, the experiment was continued in laboratory conditions. Four $20 \mathrm{~cm}$-high tanks were filled with a rock mass, containing evenly spread component of thickness - $1.0+0.1$ $\mathrm{mm}$. Every tank was fed with water the flow of which was stopped at certain intervals. The first tank was fed with water with no intermission, the second was fed for 2 days with 1-day breaks, the third one was feed day after day. In the fourth tank, the filtration flow was active primarily for 2,5 minutes until the tank was completely full, then it was stopped, but was resumed before the rock mass was drained (approximately in 1.5-2.0 min), i.e., the incomplete draining of the rock mass took place.

After 2 months, the gold was extracted from the samples selected layer by layer; its content is shown in Fig. 4.

The process of gold migration proved to be the most effective with the cycle of incomplete draining. At tank depth of $8-20 \mathrm{~cm}$, the content of gold increased by $23.2 \%$ in comparison to the original, and process water flow rate reduced by 40 and $50 \%$, respectively.

In 2017, the laboratory researches on the processes of the formation of productive areas of residue placer deposits by means of cyclic influence of filtration flow were continued.Table 1 illustrates the parameters of flood-and-drain process in three blocks of residue rock mass, the experiment lasted 125 days.

The results of the beneficiation of the samples are shown in the diagram in Fig. 5.

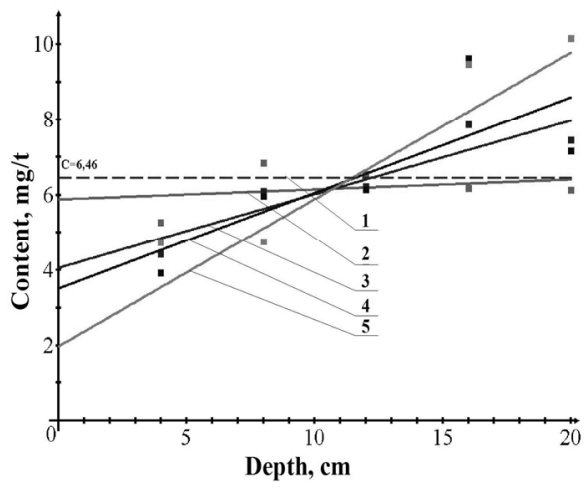

Fig. 4. The spread of gold across the depth of the rock mass: 1 - original content, 2 - with constant water supply, 3 - with cycle $2 / 1,4-$ with cycle $1 / 1,5$ - being flooded and incompletely drained.

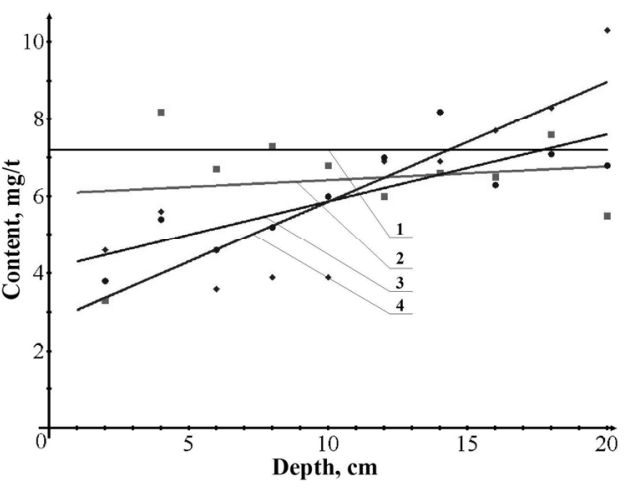

Fig. 5. The content of gold in the samples the content of gold in blocks 1, 2, 3, respectively; 1 - original state, 2 - diagram of content change in block $1,\left(\mathrm{c}_{\mathrm{c}}=0.35\right), 3$ - diagram of content change in block $3\left(\mathrm{c}_{\mathrm{c}}=0.64\right), 4-$ diagram of content change in block $2\left(\mathrm{c}_{\mathrm{c}}=0.72\right)$.

The analysis of the obtained data shows that the worst migration of gold took place in block 1 , the change in the content was mainly caused by fraction $-1.0+0.5 \mathrm{~mm}$; the migration of gold particles the thickness of which was below $0.5 \mathrm{~mm}$ is insignificant.

The change in the content of gold in tank 3 was also basically caused by fraction $1.0+0.5 \mathrm{~mm}$, although it is possible to observe the movement of gold particles from fraction $0.5+0.2 \mathrm{~mm}$ from the second and third layers being $14 \mathrm{~cm}$ deep, and the $73 \%$ increase in the content of gold in fraction $-0.2+0.1 \mathrm{~mm}$ on the bottom of the tank. The effect of gold particles migration is noticeable in tank 2 . It is possible to observe the decrease in the content of gold in fractions $-0.5+0.2$ and $-0.2+0.1 \mathrm{~mm}$, and in the 7 upper layers, the 
content increased by $28 \%$ for fraction $-0.5+0.2 \mathrm{~mm}$ and by $87 \%$ for fraction $-0.2+0.1 \mathrm{~mm}$.

Table 1. Flood-and-drain cycle parameters

\begin{tabular}{|c|c|c|c|}
\hline $\begin{array}{c}\text { Block } \\
\text { number }\end{array}$ & $\begin{array}{c}\text { Water } \\
\text { supply, min }\end{array}$ & Draining, min & Cycle duration, min \\
\hline 1 & 2 & 8 & \multirow{2}{*}{10} \\
\hline 2 & 5 & 5 & \\
\hline 3 & 8 & 2 & \\
\hline
\end{tabular}

\section{Conclusions}

It was established that the migration of gold particles in residue sands is more intensive than with more cycles of "freeze-thaw" actions. Cryogenic processes have a noticeable influence on the migration of gold of small sizes $(-0.25 \mathrm{~mm})$. It was experimentally proven that the main factor influencing the movement of the particles is filtration flow.

Under the complex influence on the rock mass, the area of gold concentration is displaced downwards, being increased by $20-64 \%$ in comparison to the influence of the water flow alone, and it also moves across the length of the dump, with the prevalent influence comes from the volume of water free flow.

On the basis of natural experimental researches it was established that after the influence on the rock mass from the water flow and its freezing in winter, the content of gold in the upper layer reduced by $62 \%$ in comparison to the original, in the lower layer it increased by $68.9 \%$. As a result of industrial testing on the test section during the two washing seasons, it was possible to form a mineral-rich layer the size of which is $44 \%$ of overall volume of sands in the block.

The migration of gold under cyclic flood-and-drain process of the rock mass is more effective; the content of gold in the laboratory research in the bottom layer increased by $43 \%$, water flow rate reduced by $50 \%$.

\section{References}

1. N. P. Laverov, K.N. Trubetskoi. Vesti RAN. 66 (5). pp. 411-418.

2. A.P. Van-Van-E, Resource base of natural-technogenic gold placer deposits. - M.: Mining book, 268 p. (2010).

3. I.U. Rasskazov, V.S. Litvintsev, U.A. Mamaev. Gold-mining industry. 1. pp. $14-20$. (2011).

4. V.S. Litvintsev. PTPDMR. 1. pp. 118 - 126. (2013).

5. G.S. Mirzekhanov, Z.G. Mirzekhanova, The resource potential of residue gold placer deposits. Max Press. p. 288. (2013).

6. V.S. Litvintsev, R.S. Seryi, T.S. Banshchikova, P.P. Sas. PTPDMR. 2. pp. 72-79. (2016).

7. R.N. Kopylov. The differentiation of gold in alluvial layer deposits / ed.-in-chief E.D. Izbekov. Yakutsk: Sakhapoligrafizdat. p. 141. (2002).

8. L.V. Pustovalov. Petrography of sediment rocks. Gostopnekhizdat. p. 476. (1940).

9. B.S. Lunev, O.B. Naumova, Atlas of placer deposits geology. 1: Factors of placer deposit formation. p. 344. (2005).

10. V.S. Alekseev, The foundation of rational technology of forming a productive area under open development of residue placer deposits of Amur River region: synopsis of thesis. candidate of technical sciences - Khabarovsk city. p. 22. (2012).

11. U.A. Mamaev, V.S. Litvintsev, V.S. Alekseev. Pacific geology. 31(4). 106-112. (2012). 